\title{
ESTUDOS CRÍTICOS EM ADMINISTRAÇÃO: A PRODUÇÃO CIENTÍFICA BRASILEIRA NOS ANOS 1990
}

\section{RESUMO}

A década de 1990 marca a emergência de um movimento de estudos críticos em administração no contexto anglo-saxão que se distingue de outras abordagens críticas pela originalidade de sua proposta. Levando em consideração a emergência e a sedimentação desse movimento, este artigo apresenta o desenvolvimento da produção acadêmica brasileira, ressalta seus avanços, suas nuanças e as possíveis contribuições para se sofisticar a pesquisa e a prática organizacional. Examinando-se, então, a produção de abordagens críticas no Brasil ao longo da década de 1990, constata-se (a) uma carência de pesquisas que aprofundem conhecimento sobre práticas e organizações locais e (b) o potencial de renovação da produção teórica em administração que tais abordagens possuem.

\section{Eduardo Davel}

Télé-université (Université du Québec) e HEC Montreal.

\section{Rafael Alcadipani}

FGV-EAESP

ABSTRACT The 90s gives rise to the emergence of a movement of Critical Management Studies in Anglo-Saxon context that distinguishes itself from other approaches by the originality of its proposals. This paper presents an overview of the advances of this movement, highlights its nuances and the possible contributions for increasing organizational research and practice in Brazil. By examining, then, the production of critical approaches in Brazil throughout the 90s, it leads us to realize a need for researches surveying in depth both knowledge and practices of local organizations.

PALAVRAS-CHAVE Estudos críticos em administração, renovação organizacional, reflexão, estudos críticos no Brasil. KEY WORDS Critical management studies, oerganizational renewal, reflection, critical studies in Brazil. 


\section{INTRODUÇÃo}

A partir da década de 1970, diferentes abordagens que ofereciam alternativas à perspectiva funcionalista, até então amplamente dominante, começaram a ganhar corpo nos estudos organizacionais (Clegg e Hardy, 1999). Entre elas, destaca-se a perspectiva crítica que se consolidou no contexto anglo-saxão, nos anos 1990, com a criação e o desenvolvimento do movimento denominado "Critical Management Studies" (Alvesson e Willmott, 1992a, 1996), ou seja, "Estudos Críticos em Administração" - ECA. No contexto brasileiro, o desenvolvimento dos estudos organizacionais, originado há aproximadamente 20 anos, caracteriza-se por seu crescimento - especialmente na década de 1990 -, por sua qualidade duvidosa (Bertero, Caldas e Wood Jr., 1999) e pela influência - ou dependência - das literaturas norte-americana e britânica (Rodrigues e Carrieri, 2000; Vergara, 2001).

Várias pesquisas sobre tal desenvolvimento (Machado-da-Silva, Cunha e Amboni, 1990; Bertero e Keinert, 1994; Martins, 1996; Vergara, 2001) indicam que falta uma visão crítica da realidade na análise organizacional brasileira, na medida em que preponderam os artigos baseados em referenciais funcionalistas e positivistas em detrimento de referenciais teóricos críticos. Assim, ao passo que as abordagens críticas em administração evoluem e ganham respaldo no contexto internacional, análises da produção acadêmica brasileira da década de 1980 e do início dos anos 1990 demonstram que a perspectiva crítica, embora tenha sido levada em conta, ainda não é muito difundida nem devidamente utilizada em nosso país.

Contudo, os estudos críticos brasileiros não são oriundos, nem uma simples conseqüência, do movimento anglo-saxão. Ao contrário, dispomos, no Brasil, de estudiosos críticos de grande profundidade e reconhecimento - por exemplo, Guerreiro Ramos, Maurício Tragtenberg e Fernando Prestes Motta - que submeteram a Administração e os Estudos Organizacionais ao crivo crítico bem antes da década de 1990, quando o movimento crítico anglo-saxão emerge de maneira articulada. Porém, as conseqüências dos escritos desses teóricos para a produção acadêmica nacional em Administração, bem como as principais características dos estudos críticos atuais, nunca foram estudadas de maneira sistemática.

Dessa forma, o objetivo deste artigo é analisar a produção acadêmica crítica em administração no Brasil durante a década de 1990, inspirando-se no desenvolvimento dos ECA e buscando traçar as principais características desse movimento. Para tanto, na primeira parte do artigo, abordaremos as origens, o desenvolvimento e a consolidação dos ECA em contexto anglo-saxão, destacando suas principais características e fundamentos teóricos. Na segunda parte, examinaremos todos os artigos publicados, durante a década de 1990, nas cinco revistas brasileiras de administração de maior destaque e nos anais do Enanpad. Finalmente, discutiremos algumas contribuições e implicações dos ECA para o avanço da pesquisa em administração.

Vale destacar que, para poder cumprir o objetivo deste artigo, precisávamos distinguir as pesquisas que são críticas daquelas que utilizam o termo crítico de forma ampla ou somente como mais um tipo de "modismo" organizacional. Para realizar tal empreitada, utilizamos os parâmetros dos Estudos Críticos em Administração (Alvesson e Willmott, 1992a, 1996; Gabriel, 2001; Antonacopoulou, 1999; Fournier e Grey, 2000), pois esse movimento já debateu e pesquisou o que define as fronteiras entre os estudos críticos e os demais. Além disso, articulou e integrou variadas perspectivas críticas, existentes anteriormente de forma dispersa.

\section{ESTUDOS CRÍTICOS EM ADMINISTRAÇÃO}

\section{0 desenvolvimento dos Estudos Críticos em Administração}

Durante a complexa reconfiguração de temáticas e abordagens pela qual passa o campo dos estudos administrativos e organizacionais, a década de 1990 marca uma rearticulação original entre os termos "crítica" e "administração" (Fournier e Grey, 2000), constituindo a emergência de uma subdisciplina denominada "Estudos Críticos em Administração". Contudo, isso não significa que a crítica de um processo disciplinar próprio ao desenvolvimento da administração e o questionamento do controle da força de trabalho sejam problemáticas recentes. Ao contrário, ao longo do século XX vários autores exploraram e discutiram o aumento do poder social da administração (Burnham, 1945; Mills, 1956; Bendix, 1956). Permeada pelas matrizes de poderes sociais e políticos, a administração foi, repetidamente, submetida ao crivo de análises críticas. Entretanto, é somente a partir da década de 1990, em meio e tradição anglo-saxões, que se reali- 
zou um esforço para unificar esse tipo de análise sob um mesmo brasão, denominado "Estudos Críticos em Administração". Esse foi o título do livro precursor no assunto, publicado no início dos anos 1990 (Alvesson e Willmott, 1992a) e que desencadeou uma proliferação de publicações, colóquios, conferências, workshops e redes acadêmicas ${ }^{1}$ concebidas para discutir aquilo que poderíamos denominar de "administração crítica".

Nesse fervor de proliferação de eventos e publicações, os ECA emergem com o objetivo de conferir a palavra àqueles e àquelas que, ao se identificarem como racionais, indiscutíveis e indubitáveis, são raramente considerado(a)s pelas teorias organizacionais tradicionais que tendem a idealizar a administração. Expondo as faces ocultas, as estruturas de controle e de dominação e as desigualdades nas organizações, a abordagem crítica busca questionar permanentemente a racionalidade das teorias tradicionais e mostrar que as coisas não são necessariamente aquilo que aparentam no âmbito da gestão.

Entretanto, uma das distinções essenciais desse movimento é que a crítica não constitui um mecanismo de descoberta da "terra prometida" da felicidade e da justiça - por exemplo, por intermédio de um ideário humanista monocultural e universalista. Ela refere-se a uma forma de atuação que favorece a reflexão, o questionamento e a renovação de situações e estruturas que impedem o desenvolvimento progressivo da autonomia e da responsabilidade social das pessoas (Alvesson e Willmott, 1996; Gabriel, 2001; Antonacopoulou, 1999). Nesse novo itinerário, os ECAs não são essencialmente contra a gestão e as organizações capitalistas, não operam por uma crítica generalizada e universalizante e não buscam um estado predeterminado de libertação do ser humano. Ao contrário, busca-se uma crítica parcial, temporária e localizada no âmbito de práticas, teorias e discursos que emergem no quotidiano das organizações.

De fato, à medida que os ECA adotam tal postura, são suscetíveis, cada vez mais, de se tornarem um recurso indispensável para os participantes da vida organizacional, podendo inspirar e sofisticar a reflexão, o questionamento e a renovação de processos, estruturas e teorias. Aproximando-se da práxis administrativa em tempo e espaço delimitados, esse novo movimento crítico pode equipar estudantes, gestores e outros profissionais com conceitos, idéias e entendimentos que funcionam como um contrapeso aos imperativos funcionais e instrumentais freqüentemente encon- trados em ambientes organizacionais. Graças ao seu enraizamento no quotidiano específico, pode, ainda, oferecer formas de viabilização do exercício da cidadania corporativa e de ações que promovam a melhoria da qualidade de vida e de trabalho, que visem à construção de relações mais democráticas e justas e que mitiguem as desigualdades e diferenças de raça, sexo ou credo (Vergara e Branco, 2001, p. 22).

\section{0 que é ser crítico para os Estudos Críticos em Administração?}

Se levarmos em conta a diversidade de abordagens e tradições teóricas que compõem a teoria administrativa, será que poderíamos considerar qualquer crítica da administração como engajada nesse campo de pesquisa? Será que ser crítico em administração significa apontar problemas e possíveis soluções? Será que mostrar que algo está incorreto e deve ser corrigido implica ser crítico? A tarefa de criticar algo ou apontar aspectos negligenciados pela abordagem funcionalista não significa ser crítico, nos termos dos ECA. No composto complexo e heterogêneo de abordagens críticas, baseando-nos em Fournier e Grey (2000) e Alvesson e Willmott (1992b, 1996), podemos estabelecer três parâmetros fundamentais para identificar um estudo como sendo de natureza crítica. Segundo esses autores, além das nuanças entre as diferentes tradições críticas em administração, variadas concordâncias e uma ampla gama de objetivos comuns permitem delimitar suas fronteiras identitárias, de ação e de pesquisa. São elas: (1) a promulgação de uma visão desnaturalizada da administração, (2) intenções desvinculadas da performance e (3) um ideal de emancipação.

\section{Visão desnaturalizada da administração}

Por intermédio do processo de naturalização - ampla e vulgarmente utilizado pelas teorias tradicionais -, a formação social é abstraída do contexto histórico e conflituoso de sua origem, sendo tratada como uma entidade concreta e relativamente fixa. Os arranjos institucionais, nesse processo, não são vistos como escolhas, mas sobretudo como arranjos naturais e evidentes por si próprios, totalmente estrangeiros às relações de poder (Alvesson e Deetz, 1999). Enquanto as teorias administrativas do século XX se engajam em um duplo movimento de construção da realidade organizacional e de ornamentação dessa realidade com racionalidade, cientificidade e naturalização, os ECA são, em contrapartida, engajados no questionamento sistemático de tal edifício teórico (Fournier e Grey, 
2000). Assim, os ECA consideram a organização como uma construção sócio-histórica, tornando-se importante compreender como as organizações são formadas, consolidadas e transformadas no interior e no exterior.

\section{Intenção desvinculada da performance}

Outro traço fundamental dos ECA se deve ao fato de que tais estudos não buscam desenvolver conhecimentos que contribuam para a maximização de outputs contra um mínimo de inputs. Ou seja, os ECA não visam a celebrar conhecimentos inscritos em uma lógica instrumental de cálculo dos meios com relação aos fins ou que melhorem o desempenho econômico das organizações. Os estudos considerados como não críticos obedecem ao princípio da performance que subordina o conhecimento à eficiência, à eficácia e à lucratividade. Em uma perspectiva não crítica, a performance refere-se a um imperativo em torno do qual todo conhecimento ou prática deve ser gerado, sem jamais deixar espaço a questionamentos nem a dúvidas. O desenvolvimento de uma pesquisa na abordagem crítica não se preocupa em gerar conhecimento em função da melhoria da performance econômica da organização. Seu foco está na tentativa de emancipar as pessoas dos mecanismos de opressão, tendo, de fato, o humano como ponto fundamental.

\section{Intenção emancipatória}

Os ECA procuram enfatizar, nutrir e promover o potencial da consciência humana para refletir de maneira crítica sobre as práticas opressivas, facilitando, assim, a extensão dos níveis de autonomia e responsabilidade das pessoas. Por autonomia entende-se a capacidade dos seres humanos produzirem julgamentos que não sejam impedidos ou deformados por dependências sociais inúteis associadas à subordinação e às desigualdades de riqueza, de poder e de conhecimento. Por responsabilidade entende-se o desenvolvimento de uma consciência de nossa interdependência social e, conseqüentemente, a compreensão de nossa responsabilidade coletiva para com os outros. A transformação emancipatória opera-se, então, à medida que as pessoas procuram mudar - pessoal, coletiva e progressivamente - seus hábitos e as instituições que impedem o desenvolvimento de sua autonomia e de sua responsabilidade (Alvesson e Willmott, 1996).

Resumidamente e de forma geral, podemos perceber que a teoria crítica visa a favorecer um desenvolvimento racional e democrático das instituições modernas, nas quais cidadãos responsáveis, auto-reflexi- vos e autônomos se tornam progressivamente menos dependentes de receber entendimentos sobre suas necessidades. Eles tornam-se menos direcionados pela aparente naturalidade e inevitabilidade da ordem político-econômica prevalecente (Alvesson e Willmott, 1996). Permanece subjacente a esse processo de desenvolvimento uma visão da emancipação que é de natureza parcial e realizável na administração e nas práticas organizacionais de todos os dias, buscando promover teorias e práticas administrativas que carreguem menos exclusão e dominação (Watson, 1994; Alvesson e Willmott, 1996; Anthony, 1998). A abordagem crítica adotada pelos ECA não pretende solucionar de forma definitiva o problema da dinâmica social e política que modela a maneira como as pessoas pensam, ressentem-se e agem. Ela busca operar no fluxo diário das práticas opressivas, dominantes e excludentes que, inutilmente, atrapalham o desenvolvimento pessoal e coletivo no âmbito organizacional.

\section{Perspectivas críticas}

Tendo como pano de fundo o paradigma radical humanista e radical estruturalista (Burrell e Morgan, 1979), o corpo teórico que nutre o desenvolvimento dos ECA perpassa uma pluralidade de tradições intelectuais das ciências sociais (por exemplo, Jermier, 1998), gerando uma arena de debates em que os críticos se criticam. Nessa arena intelectual de debates e tensões, podemos destacar três grandes conjuntos de tradições teóricas que têm sido, regularmente, mencionados como eixos de sua dinâmica (Fournier e Grey, 2000; Alvesson e Deetz, 1999). O primeiro conjunto engloba as tradições modernistas desenvolvidas no âmbito do marxismo, do neomarxismo e da Escola de Frankfurt. O segundo envolve o que - baseados na proposta de Jacobson e Jacques (1997, p. 56) - denominamos de tradições pós-analíticas. Para esses autores, o termo "abordagens pós-analíticas" é apropriadamente impreciso, com a finalidade de se referir às múltiplas correntes contemporâneas do pensamento social - por exemplo, pós-estruturalismo, pós-modernismo, pós-colonialismo - que podem ser unidas somente por aquilo que as diferencia: o conhecimento analítico. O terceiro grupo engloba as teorias feministas. Esses três conjuntos teóricos constituem o corpo dinâmico dos ECA porque representam críticas efetivas do pensamento positivista, da noção de progresso e das formas mais sofisticadas de controle, ideologia e dominação. Todos comungam da busca pelo questionamento dos pressupostos tomados como verdadeiros 
sobre as formas como as pessoas escrevem, lêem e praticam a administração.

Os estudos críticos influenciados pela tradições modernistas tendem a salientar (a) que vivemos em um mundo repleto de dores e conflitos, (b) que muito pode ser feito para aliviar tais dores e (c) que os teóricos e a teoria crítica desempenham um papel crucial nesse processo (Poster, 1989). O projeto pós-analítico distingue-se dessas tradições, sobretudo, por rejeitar não somente as metanarrativas sobre a realidade social, mas também por abortar uma posição do humano como ser totalmente racional (Cooper e Burrell, 1988). Dessa forma, para a perspectiva pós-analítica, os significados são conferidos às ações dentro de uma rede social que pode ser lida como se fosse um texto. A trama textual e discursiva da vida organizacional, ao constituir os parâmetros para aqueles que se mobilizam dentro da teia de relações organizacionais (Jacobson e Jacques, 1997, p. 48), leva os estudiosos pós-analíticos a refletirem e questionarem sobre as formas como certos textos destacam, privilegiam e expõem algumas dimensões da vida organizacional, marginalizando, escondendo ou descartando outras dimensões. Fundado nessas duas tradições intelectuais ou em uma delas, as teorias feministas enfocam as questões de como e por que a exclusão ou a opressão das mulheres acontece no âmbito das organizações para, a partir daí, elaborar formas de se lidar com tais situações (Alvesson e Billing, 1997; Calás e Smircich, 1999).

Acompanhando o desenvolvimento dos ECAs na década de 1990 em contexto anglo-saxão, é possível notar um certo aprofundamento e especialização das análises críticas. Alvesson e Willmott (1996) destacam a importância de se efetuar uma análise crítica das diferentes especialidades da administração marketing, sistemas de informação, pesquisa operacional, contabilidade etc. Por exemplo, Townley (2001) e Knights e Morgan (1991) submeteram a uma análise crítica, respectivamente, as áreas de RH e estratégia empresarial. Com efeito, Davel e Chennoufi (2001), em uma análise de 242 artigos de orientação crítica apresentados em três congressos academicamente reconhecidos em administração, encontraram 12 subcampos de especialização da análise crítica em administração: organizações, marketing, estratégia, contabilidade, tecnologia da informação, tecnologia e conhecimento, métodos, ensino e aprendizagem, indústria cultural, cultura popular, globalização, e meio ambiente. Esse estudo indica, então, que os ECA se desenvolvem em contexto anglo-saxão de maneira especializada, elaborando e fornecendo uma análise minuciosa e cada vez mais adaptada aos subsegmentos da administração.

Em suma, os ECA buscam engajar as pessoas - por exemplo, pesquisadores, gerentes, teóricos - em uma via de conhecimento sempre renovado e condizente com o ideal de emancipação individual e coletiva, incitando o desenvolvimento de sensibilidades críticas com relação à retórica, à tradição, à autoridade e à objetividade (Mingers, 2000) do projeto de edificação das concepções ortodoxas das teorias administrativas. Análises pormenorizadas ou especializadas das subáreas da administração têm por finalidade encorajar a reflexão e evitar a complacência e a suficiência. Nesse sentido, a crítica torna-se um hábito ligado à práxis e à experiência vivida, ao invés de se estabelecer como um processo motivado somente por uma atividade cerebral (Gabriel, 2001).

\section{O DESENVOLVIMENTO DOS ECA NO BRASIL}

Com a finalidade de melhor compreender o desenvolvimento dos ECA no Brasil, seguimos o procedimento de análise de outras pesquisas que examinaram a literatura em administração e /ou estudos organizacionais (Machado-da-Silva, Cunha e Amboni, 1990; Bertero e Keinert, 1994; Dellagnelo e Machado-da-Silva, 2000). Logo, a unidade de análise considerada é de artigos acadêmicos e o universo da pesquisa inclui todos os artigos encontrados nos periódicos nacionais que contenham evidências de serem críticos com relação aos parâmetros anteriormente elaborados. A busca de artigos críticos foi realizada nos seguintes periódicos: Revista de Administração de Empresas (RAE), Revista de Administração Contemporânea (RAC), Revista de Administração Pública (RAP), Revista de Administração (RAUSP) e revista Organização \& Sociedade (OES), bem como nos Anais do Enanpad. Vale ressaltar que todas as áreas temáticas foram analisadas, pois se pretendia verificar os estudos em administração. Esses periódicos foram escolhidos por serem os mais conceituados na área de organizações e administração no Brasil. No que tange aos Anais do Enanpad, a escolha se deu devido ao fato de esse fórum ser o mais expressivo e respeitado encontro de pesquisadores em administração do país. O período de análise escolhido foi de 1990 até 2000, por representar a época em que houve a consolidação dos ECA no plano internacional. 
Para classificar um artigo como eminentemente crítico, buscamos identificar se os três parâmetros definidores das fronteiras dos ECA aí estavam presentes - visão desnaturalizada da administração, não preocupação com performance e intenção emancipatória - e se a base da argumentação era realizada dentro das matrizes epistêmicas de orientação crítica - tradição modernista, pós-analítica e /ou feminista. Esses critérios foram operacionalizados pelo uso das questões na Tabela 1. De 3.702 artigos analisados, 80 artigos (2,16\%) foram selecionados como sendo críticos (Tabela 2). Na análise que fizemos de cada um desses 80 artigos selecionados, buscamos examinar quais eram as temáticas abordadas, as influências teóricas mais preponderantes, o tipo de metodologia utilizada e a instituição do primeiro autor dos artigos. Tomamos como parâmetros para a análise das influências teóricas os três conjuntos de tradições teóricas que encontramos na literatura disponivel sobre os ECA. No que se refere à análise dos aspectos metodológicos dos artigos avaliados, tomamos como referência, fundamentalmente, três tipos de metodologias: (a) aquelas que se concentram em um âmbito puramente conceitual, (b) aquelas que privilegiam uma abordagem sumária do(s) caso(s) estudado(s) e (c) aquelas que privilegiam um contato mais aprofundado com o objeto empírico de estudo. Passaremos, então, à apresentação e discussão dos resultados encontrados para cada uma dessas dimensões.

Tabela 1 - Critérios de seleção dos artigos críticos.

\begin{tabular}{|l|l|l}
\hline \multicolumn{1}{|c|}{ CRITÉRIOS } & \multicolumn{1}{c}{ QUESTÕES-CHAVE } \\
\hline $\begin{array}{l}\text { Visão } \\
\text { desnaturalizada }\end{array}$ & $\begin{array}{l}\text { A organização e /ou a teoria são tratadas como sendo inseridas em um contexto sócio-histórico espe- } \\
\text { cífico, como entidades relativas? }\end{array}$ \\
& $\begin{array}{l}\text { O discurso organizacional é apresentado como sendo suscetível de falhas, contradições e incongruências? } \\
\text { Os aspectos de dominação, controle, exploração e exclusão na teoria ou na prática são revelados e /ou } \\
\text { questionados? }\end{array}$ \\
\hline $\begin{array}{l}\text { Desvinculação } \\
\text { da performance }\end{array}$ & $\begin{array}{l}\text { A preocupação com a melhoria de ganhos pecuniários, performance, rentabilidade, lucratividade e /ou } \\
\text { produtividade orienta a pesquisa? }\end{array}$ \\
\hline $\begin{array}{l}\text { O conhecimento gerado está submetido às questões de melhoria da performance, eficiência, eficácia e / } \\
\text { ou lucratividade? }\end{array}$ \\
\hline Intenção \\
emancipatória
\end{tabular}

Tabela 2 - Aspectos metodológicos e estatísticos.

\begin{tabular}{|c|c|c|c|c|}
\hline \multirow[t]{2}{*}{ LITERATURA EXAMINADA } & \multirow[t]{2}{*}{ PERIOODO ANALISADO } & \multicolumn{3}{|c|}{ ARTIGOS } \\
\hline & & TOTAL & CRITICOS & $\%$ \\
\hline O\&S & 1993 (v. 1, n. 1) - 2000 (v. 7, n. 18 ) & 134 & 8 & 6 \\
\hline RAP & 1990 (v. 24, n. 1) - 2000 (v. 34, n. 4 ) & 417 & 16 & 4 \\
\hline RAE & 1990 (v. 30, n. 1) - 2000 (v. 40, n. 4) & 434 & 18 & 4 \\
\hline RAC & 1997 (v. 1, n. 1) - 2000 (v. 4, n. 3 ) & 88 & 3 & 3 \\
\hline RAUSP & 1990 (v. 15, n. 1) - 2000 (v. 25, n. 4 ) & 412 & 8 & 2 \\
\hline \multirow[t]{2}{*}{ Enanpad } & $1990-2000$ & 2217 & 27 & 1 \\
\hline & Total & 3702 & 80 & 2 \\
\hline
\end{tabular}




\section{Apresentação dos resultados}

Apesar dos baixos percentuais de publicação de pesquisas críticas no contexto brasileiro, uma análise temporal mostra o aumento discreto de tal produção: contra dois artigos publicados em 1992, foram apresentados 14 artigos em 1997 e 17 em 2000. Proporcionalmente à quantidade de artigos publicados, a revista Organização \& Sociedade, publicada pela UFBA (6\%), a Revista de Administração Pública, publicada pela FGV-EBAPE (4\%), e a Revista de Administração de Empresas da FGV-EAESP (4\%) são as que mais têm divulgado as pesquisas que utilizam abordagens críticas no Brasil. Entretanto, se levarmos em conta a instituição de origem do primeiro autor dos artigos analisados, notamos que a FGV-EAESP $(21,25 \%)$ e a FGV- EBAPE $(17,5 \%)$ aparecem como as instituições com maior percentual de artigos críticos, seguidas pela UFBA $(13,75 \%)$. Vale sublinhar que a proporção significativa de artigos críticos publicados por autores pertencentes a instituições internacionais é de $10 \%$.

\section{Temáticas abordadas}

As temáticas que emergem dos artigos examinados demonstram a diversidade de assuntos analisados pelos críticos brasileiros. A Tabela 3 indica que as temáticas de dominação, ideologia, controle, disciplina, gênero, exclusão social, cidadania, sofrimento psíquico e físico são as mais recorrentes. Dentre elas, a questão da prática e da teoria organizacionais como sistemas de dominação e de ideologia é a que parece mais ocupar a atenção dos estudiosos (36\%). A preponderância de tais temáticas é influenciada pelos autores brasileiros que avaliaram o desenvolvimento da teoria organizacional, levando em conta seus aspectos instrumentais e normativos (Ramos, 1981, 1983), ideológicos (Tragtenberg, 1974, 1980; Prestes Motta, 1986, 1992), disciplinares, de controle e de dominação (Prestes Motta, 1981; Segnini, 1988). Assim, a alta concentração de estudos sobre a temática da dominação e da ideologia decorre das análises brasileiras existentes sobre: (a) a teoria administrativa como ideológica, refletindo os interesses das classes dominantes (Tragtenberg, 1974) e mascarando a exploração sofrida pelos trabalhadores (Tragtenberg, 1980) e (b) a produção e a transmissão de ideologias pela organização, elemento fundamental para a manutenção do poder pela classe dos tecnoburocratas (Prestes Motta, 1986, 1992).

No que se refere às temáticas de pesquisa mais re- correntes, constata-se que elas vão se ramificando e se adaptando aos novos discursos e práticas administrativas implementadas ao longo da década de 1990. Isso representa um aspecto original da produção crítica brasileira, já que se examina de forma mais focada as novas modalidades ideológicas e de dominação. Por exemplo, vários artigos contribuem para melhor se compreender as formas de dominação pelo simbolismo, pelo imaginário social, pela identidade social, pela subjetividade, pela figura materna, pelas práticas de Administração de Recursos Humanos, pelo discurso de metas, dentre outras. No que se refere à temática da ideologia, as pesquisas tendem, globalmente, a enfocar de que maneira a "burocracia flexível", as teorias pós-fordistas, os meios de comunicação, a qualidade total, a reengenharia e as novas tecnologias constituem-se em mecanismos ideológicos e de controle no âmbito da organização. Sobre a questão do controle social, além da influência do autoritarismo no comportamento gerencial e no processo decisório, podemse ressaltar as pesquisas que apresentam a avaliação de desempenho, os escritórios abertos, o "jeitinho brasileiro" e a cultura forte como mecanismos de controle e de poder disciplinar.

Por fim, a análise do conjunto de artigos publicados conduz-nos a perceber que as temáticas de gênero, exclusão social, cidadania e sofrimento também ocupam, mesmo que modestamente, a pauta de pesquisa da produção brasileira. As temáticas relacionadas aos aspectos de gênero nas organizações e na administração tendem a privilegiar as questões de subutilização do potencial feminino, as dificuldades de ascensão na carreira e de auto-afirmação pessoal e profissional. Com relação aos estudos sobre o sofrimento, que contabilizam 4\% do conjunto dos artigos publicados, os autores indicam, freqüentemente, como o sofrimento psíquico pode ser ocasionado por tarefas que não são socialmente valorizadas e como sofrimento e prazer estão associados a determinadas formas de regulação de conflitos.

\section{Influências teóricas}

Além do desdobramento dessa diversidade de temáticas abordadas pelos artigos analisados, identificamos a influência teórica dominante em cada artigo analisado. Como indica a literatura sobre os ECAs em contexto anglo-saxão, consideramos três conjuntos de tradições: as modernistas, as pós-analíticas e as feministas. Os resultados mostram que as tradições modernistas ainda exercem alta influência na forma de 
conceber e conduzir a crítica em administração no Brasil (Tabela 4). Isso se deve, provavelmente, à considerável influência que o marxismo e as ciências sociais em geral tiveram no pensamento administrativo brasileiro (Bertero, 2000), mantendo uma visão pre- ponderantemente materialista das relações de poder no contexto organizacional.

As tradições pós-analíticas (26\%) e feministas (13\%) não tiveram muita influência sobre a produção acadêmica dos artigos publicados nos periódicos em admi-

Tabela 3 - Temas recorrentes nos ECA brasileiros.

\begin{tabular}{|c|c|c|c|}
\hline TEMAS & N. & $\%$ & EXEMPLOS \\
\hline $\begin{array}{l}\text { Dominação } \\
\& \text { ideologia }\end{array}$ & 32 & 36 & $\begin{array}{l}\text { "Tudo leva a crer que o estudo sistemático das funções ideológicas da empresa explique bastante } \\
\text { decisões e aspectos que à primeira vista padecem de sentido, bem como a forma pela qual os indivíduos } \\
\text { vêm-se relacionando com as organizações, desenvolvendo um tipo de personalidade, e experimentando } \\
\text { e lidando com novas formas de angústia e de satisfação" (Prestes Motta, 1992, p. 47). } \\
\text { "A qualidade total trabalha o recalcamento, pois cria um lugar simbólico-imaginário conveniente à } \\
\text { sua ideologia, em que o indivíduo pode, sem culpa, ignorar suas impossibilidades. A dominação } \\
\text { psicossocial que se encontra por debaixo dos programas de qualidade cria as condições para que o } \\
\text { indivíduo confie, idealize e comprometa-se com a organização" (Faria e Oliveira, 1999, p. 9). }\end{array}$ \\
\hline $\begin{array}{l}\text { Controle } \\
\text { \& disciplina }\end{array}$ & 11 & 12 & $\begin{array}{l}\text { "Enquanto instituição cultural brasileira, o jeitinho exerce um nítido papel de controle social" (Pres- } \\
\text { tes Motta e Alcadipani, 1999, p. 8). } \\
\text { "Vemos a cultura organizacional como um poderoso mecanismo de controle, que visa a conformar } \\
\text { condutas, homogeneizar maneiras de pensar e viver a organização, introjetando uma imagem posi- } \\
\text { tiva dela, em que todos são iguais, escamoteando as diferenças e os conflitos inerentes a um } \\
\text { sistema que guarda antagonismos e anulando a reflexão" (Freitas, 1996, p. 6). }\end{array}$ \\
\hline Gênero & 11 & 12 & $\begin{array}{l}\text { "As vantagens que a carreira oferece faz com que elas [as mulheres na Polícia Civil de Salvador] se } \\
\text { sintam integradas, suportem a carga horária excessiva e escamoteiem os problemas domésticos. } \\
\text { Elas se sentem ao mesmo tempo 'realizadas' e 'felizes', mas 'cansadas', 'estressadas' e conforma- } \\
\text { das com a situação doméstica” (Bahia e Ferraz, 2000, p. 38-9). } \\
\text { “Muito embora as sociedades ocidentais estejam progressivamente incrementando e } \\
\text { operacionalizando o discurso igualitário entre homens e mulheres, mudanças são escassas quan- } \\
\text { do se analisa a divisão hierárquica do trabalho" (Steil, 1997, p. 62). }\end{array}$ \\
\hline $\begin{array}{l}\text { Exclusão social } \\
\& \text { cidadania }\end{array}$ & 6 & 6 & $\begin{array}{l}\text { "A emergência de novas políticas no âmbito dos governos subnacionais indica que as reformas } \\
\text { orientam para a democratização do acesso a serviços públicos e para a ampliação da cidadania" } \\
\text { (Farah, 1998, p. 51). }\end{array}$ \\
\hline $\begin{array}{l}\text { Sofrimento } \\
\text { psíquico \& físico }\end{array}$ & 4 & 4 & $\begin{array}{l}\text { "O problema psicopatológico essencial decorre das pressões psíquicas ocasionadas pela separa- } \\
\text { ção taylorista entre as atividades de concepção e de execução, pois, confiscando dos trabalhado- } \\
\text { res a concepção de seu trabalho, a organização científica do trabalho origina uma clivagem entre } \\
\text { corpo e pensamento" (Lunardi e Mazzilli, 1996, p. 64). }\end{array}$ \\
\hline Vários & 15 & 17 & $\begin{array}{l}\text { Autonomia \& autogestão; crítica da teoria organizacional; alienação; novas tecnologias \& condi- } \\
\text { ções de trabalho; organizações substantivas. }\end{array}$ \\
\hline Vários & 4 & 4 & Autoritarismo \& processo decisório; terceiro setor. \\
\hline Vários & 8 & 9 & $\begin{array}{l}\text { Paternalismo; globalização; mídia \& comunicação; etnia; luta de classes, motivação; liderança; } \\
\text { tempo. }\end{array}$ \\
\hline
\end{tabular}


nistração. Esses são indicativos surpreendentes, quando se leva em conta que o Brasil é uma sociedade imersa em uma herança patriarcal significativa que privilegia a comunicação oral. Gênero e linguagem não deixam de ser dois aspectos centrais da formação históricosocial brasileira. Nota-se que, em número reduzido, alguns autores começam a se apropriar das abordagens pós-analíticas para estudar a natureza discursiva das relações de poder que se constróem pela e para a administração nas organizações. Por exemplo, Lengler, Vieira e Fachin (2000), baseando-se na teoria de Jacques Derrida, desconstróem o conceito de segmentação de mercado em seus aspectos de gênero e de etnia. Outro exemplo é o estudo de Alcadipani e Almeida (2000) sobre o escritório aberto como espaço do pan-óptico, onde o olhar regula a microfísica do poder disciplinar existente entre os membros da organização pesquisada.

\section{Metodologias utilizadas}

Outra dimensão analisada que merece destaque é o tipo de metodologia utilizada pelos pesquisadores. Nossa análise dessa questão levou em conta três parâmetros: (1) estudos conceituais, (2) estudos sumários de caso e (3) estudos de caso em profundidade. Com base nessa classificação, nota-se que a maioria (67\%) dos artigos analisados privilegia a argumentação teórica, os ensaios e a revisão de literatura. Isso demonstra que, no Brasil, as pesquisas em administração de orientação crítica dão preferência à discussão conceitual de problemáticas organizacionais. Em contrapartida, nota-se que os estudos críticos que aprofundam a relação com o objeto empírico de pesquisa - por exemplo, etnografias - são raros (1\%). Essa disparidade e essa baixa quantidade de pesquisas empíricas poderiam, inclusive, levar-nos a questionar até que ponto, no Brasil, a construção de uma tradição crítica de análise não estaria desengajada ou mal informada sobre a realidade específica, localizada e cotidiana das organizações, visto que os estudos de caso ainda são empregados por um terço dos pesquisadores.

\section{FORCAS E CARÊNCIAS DOS ESTUDOS CRÍTICOS BRASILEIROS}

O exame de temáticas, influências teóricas e metodologias privilegiadas pelos pesquisadores permite identificar traços originais e ausentes na produção brasileira. Trataremos, a seguir, desses aspectos.

Tabela 4 - Engajamentos teóricos nos ECA brasileiros.

\begin{tabular}{|c|c|c|c|}
\hline $\begin{array}{c}\text { TRADIÇÃO } \\
\text { INTELECTUAL }\end{array}$ & N. & $\%$ & EXEMPLOS \\
\hline Modernistas & 49 & 61 & $\begin{array}{l}\text { "Teorias organizacionais explicam e prescrevem modelos em bases da razão subjetiva, porém em } \\
\text { uma realidade social cujo paradigma é a razão instrumental” (Carneiro, 1995, p. 51). } \\
\text { "As organizações são conjuntos práticos voltados para a produção e reprodução de determinadas } \\
\text { relações sociais necessárias à manutenção e à expansão do sistema econômico vigente. As rela- } \\
\text { ções sociais que se reproduzem nas organizações são econômicas, sociais e ideológicas" (Prestes } \\
\text { Motta, 1992, p. 38). }\end{array}$ \\
\hline Pós-analíticas & 20 & 26 & $\begin{array}{l}\text { "0 conceito de segmentação de mercado e sua prática encerram em si um conjunto de atores e } \\
\text { vozes marginalizadas" (Lengler, Vieira e Fachin, } 2000, \text { p. } 1 \text { ). } \\
\text { "Por ser aberto, o escritório fazia com que todos estivessem sob os olhares de todos durante } 0 \\
\text { tempo inteiro em que estavam trabalhando. As pessoas, do presidente ao estagiário, eram facil- } \\
\text { mente localizáveis: bastava levantar a cabeça e se podia enxergar quem quisesse e saber se ele } \\
\text { estava em sua mesa ou não" (Alcadipani e Almeida, } 2000, \text { p. 13). }\end{array}$ \\
\hline Feministas & 10 & 13 & $\begin{array}{l}\text { "Mulheres raramente são educadas para posição de mando" (Barroso, 1990, p. 17). } \\
\text { "Nas estruturas organizacionais mais horizontais, como no caso das ONGs, existe maior consciên- } \\
\text { cia de gênero" (Castro, 1998, p. 2). }\end{array}$ \\
\hline
\end{tabular}




\section{A força da tradição crítica preexistente em administração}

O uso freqüente de referenciais brasileiros críticos como quadro conceitual para a realização de pesquisa indica que os estudos em administração no Brasil não estão totalmente atrelados às correntes internacionais recentes. Eles desenvolvem-se antes e mantêm uma certa distância da expansão dos ECA em contexto internacional. Isso pode se tornar uma força na medida em que se valoriza a existência, desde o final da década de 1960 , de um pensamento crítico em administração relativamente original por exemplo, Alberto Guerreiro Ramos, Maurício Tragtenberg e Fernando C. Prestes Motta. Todavia, isso não significa que possuímos um pensamento crítico totalmente autônomo em relação ao que foi produzido no exterior, pois a influência de referenciais estrangeiros clássicos é altamente significativa - por exemplo, Max Weber, Karl Marx e Sigmund Freud. Muitos daqueles teóricos realizaram leituras originais sobre a obra de autores clássicos, principalmente de Max Weber (Tragtenberg, 1974), e construíram diálogos singulares entre tradições vistas como antagônicas, como foi o caso da junção das abordagens de Max Weber e de Karl Marx (Tragtenberg, 1974; Prestes Motta, 1986).

\section{A força da diversidade e atualidade das propostas críticas}

Mesmo que a produção crítica em administração no Brasil seja discreta $(2,16 \%)$ em relação às outras abordagens, as análises críticas da década de 1990 exploram de forma mais pormenorizada e atual variadas formas de dominação - pelo simbolismo, pelo imaginário, pela subjetividade, pela figura materna, pelas práticas de $\mathrm{ARH}$ - e de mecanismos de controle e poder disciplinar - a avaliação de desempenho, os escritórios abertos, o "jeitinho brasileiro", a cultura forte, a burocracia flexível, os meios de comunicação, a qualidade total, a reengenharia, as novas tecnologias. Essa pluralidade de assuntos e propostas revela que existe uma análise crítica brasileira que tende a se especializar na avaliação de temáticas organizacionais locais cada vez mais atuais. Observamos também que essas avaliações são influenciadas por uma concepção preponderantemente materialista das relações de força e poder, em geral ligada às tradições da Escola de Frankfurt, do marxismo e do neomarxismo. As teorias freudiana e weberiana são, também, freqüentemente referenciadas.

\section{A carência de influências pós-analíticas e feministas}

Uma das carências encontradas diz respeito ao emprego de perspectivas pós-analíticas. De fato, as perspectivas feministas e pós-analíticas parecem ser timidamente utilizadas. Qual seria o efeito disso quando se considera que a centralidade da linguagem, da maleabilidade dos comportamentos - por exemplo, do "jeitinho" - e do patriarcado são fatores-chave de compreensão da formação sócio-histórica do Brasil? A literatura brasileira carece, então, de um aprofundamento teórico e empírico que instigue questionamentos acerca, por exemplo, de como os fenômenos organizacionais: (a) são criados pela interseção entre corpos, poder e conhecimento e (b) são mediados pela linguagem (Jacobson e Jacques, 1997; Hassard, Holliday e Willmott, 2000).

\section{A carência de estudos empíricos em profundidade}

Uma outra carência consiste nos métodos de pesquisa privilegiados pelos estudiosos críticos. Há um predomínio de artigos ensaísticos e uma quantidade inexpressiva de estudos de caso em profundidade (1\%). No mais das vezes, os ensaios tendem a ser norteados pela reutilização de conceitos de pensadores críticos, sem que haja a preocupação de rever o que foi escrito anteriormente sobre o assunto nem de procurar saber se tais conceitos estão ou não adequados à realidade atual. Isso pode nos levar a pensar que a crítica serve muito mais como um instrumento retórico de discussão entre teóricos do que algo que esteja, de fato, voltado para a transformação da realidade social das organizações e da administração contemporâneas. Em decorrência disso, observa-se também a ausência, quase total, de análises mais precisas e localizadas sobre as diferentes especialidades do campo da teoria administrativa. Será que a teoria da administração crítica desenvolvida estaria distante da realidade cotidiana das organizações brasileiras?

\section{A carência de estudos com incidência prática}

Dentre os artigos examinados, raros foram aqueles que se estruturaram em torno de um ideal de análise pormenorizada e localizada, empírica e teórica, no intuito de habilitar o máximo possível a reflexão, o questionamento e a atuação frente a práticas opressivas. Uma das interpretações possíveis dos propósitos fundamentais da crítica é conduzir estudiosos, gestores e profissionais: (a) a identificar e provocar os pressu- 
postos embutidos em formas corriqueiras, naturalizadas, de percepção, concepção e ação; (b) a reconhecer a influência da história, da cultura e da posição social nas crenças e ações difundidas; (c) a imaginar e explorar alternativas que alterem rotinas e a ordem estabelecida de atividades e situações; e (d) a adotar uma postura apropriadamente cética sobre todo e qualquer conhecimento ou solução que se reivindique como sendo a única verdade ou alternativa no âmbito da administração e das organizações. Até que ponto os ECAs brasileiros estariam aptos a desempenhar esse papel?

Uma das formas de obter tal incidência prática é sugerida por Alvesson e Willmott (1996) e Alter (2001). Para esses autores, os ECA podem funcionar como uma fonte de inspiração para que as pessoas reflitam sobre a escolha de carreira, sobre a tomada de decisões e sobre o processo de inovação. Ou seja, os ECA podem conduzir gerentes e outros profissionais a considerar as consequêencias de seu trabalho para um conjunto mais amplo de pessoas e levar em consideração durante a tomada de decisão os efeitos que daí decorrem (Alvesson e Willmott, 1996). Podem também fornecer uma visão de que, para inovar, é necessário transgredir o que é considerado como verdade estabelecida, aceitando os riscos existentes na relação com os colegas, com as regras de gestão e com a avaliação do trabalho (Alter, 2001). Nessa concepção, não há inovação organizacional sem o desenvolvimento de um espírito crítico apurado que ouse desvendar outras interpretações para a realidade social, instaurando novas possibilidades de ações que permitam às pessoas exercerem sua autonomia e sua consciência de interdependência social.

\section{CONCLUSÕES}

Neste artigo, a capacidade de refletir criticamente, de questionar e de renovar processos e estruturas organizacionais foi explorada e apreciada por intermédio de um movimento intitulado "Estudos Críticos em Administração". À medida que vamos conhecendo melhor as propostas desse movimento, embora alguns mais ortodoxos considerem a administração como objeto a ser destruído, outra grande gama de estudiosos críticos a considera como um espaço em que se torna possível o exercício constante de níveis progressivos de reflexão, questionamentos e renovação de situações e estruturas organizacionais que impedem o desenvolvimento da autonomia e da responsabilidade social das pessoas.

Com efeito, o exame dos ECA conduz-nos a acreditar em seu potencial para aperfeiçoar e inspirar a pesquisa em administração, tornando-a mais consciente e reflexiva. Assim, sua contribuição fundamental é enfatizar a interpenetração das dimensões técnicas e práticas da vida social, questionando o senso comum de discursos e práticas organizacionais estabelecidos que subordinam, totalmente, a prática administrativa à racionalidade técnica e instrumental. Nessa ênfase, ao revelar tanto o positivo quanto o negativo, a crítica permite-nos evitar o argumento da escolha única e indubitável. É dessa forma que uma orientação crítica pode gerar novas formas de pensamento e de expressão, avançando em reivindicações e questionando, periodicamente, por que a realidade social se apresenta de tal maneira e não de outra. Por isso, a abordagem crítica tem o poder de promover nas pessoas uma postura de vigilância, de reflexão e de questionamento sobre o que se veicula no plano da teoria administrativa e da prática organizacional. Pela reformulação constante da consciência, os ECA podem, então, estimular o que é habitualmente considerado como verdade absoluta e única alternativa, inspirando e agregando novas formas de pensar e de agir face aos paradoxos e às contradições da vida cotidiana das organizações.

Ao nos debruçarmos sobre a produção brasileira em ECA na década de 1990, percebemos que as abordagens críticas são ainda muito discretas. Nosso estudo identifica forças e carências dessa produção. Conforme observamos, apesar de atualizarem as temáticas de estudo com relação às teorias importadas do exterior, os estudiosos brasileiros refletem e questionam os acontecimentos administrativos e organizacionais de forma genérica e ampla, sem muito conhecimento e aprofundamento de realidades localizadas no tempo e no espaço. Pela influência marcante das tradições modernistas, a abordagem crítica brasileira ainda é orientada pela determinação de grandes estruturas, carecendo de questionamentos sobre: (a) a verdade dita absoluta das teorias administrativas, sejam elas de natureza crítica ou não, (b) o ritmo cotidiano e discursivo das práticas organizacionais e (c) as questões vinculadas a gênero.

Este artigo privilegia uma tomada de consciência sobre o que foi produzido e de que forma se deu a trajetória de estudos críticos em administração no Brasil ao longo da década de 1990. Com essa pesquisa, 
buscamos estimular um debate em torno da relevância de incluir abordagens críticas na análise das organizações e da administração contemporânea no país. Buscamos também identificar forças e carências dessa produção no intuito de estimular a reflexividade dos estudiosos a respeito de como tomar iniciativas para que os ECA brasileiros se renovem, se revigorem e encontrem caminhos originais a seguir. Permanece, assim, o convite aos interessados para se criar um espaço de debate e reflexão cada vez mais propício ao desenvolvimento de pesquisas e análises organizacionais mais conscientes, refletidas e próximas da realidade nacional e local.

\section{Artigo recebido em 28.02.2002. Aprovado em 06.02.2003.}

\section{Nota}

${ }^{1}$ O colóquio da British Academy of Management integrou uma sessão temática sobre a administração crítica em 1996, 1999 e 2000. Periódicos tradicionalmente ortodoxos, como o Administrative Science Quarterly (1998), realizaram um número temático sobre teoria crítica. A mesma temática figura desde 1998 no centro das discussões em um dos workshops do Encontro Anual da Academy of Management. Um fórum de discussão pela Internet sobre os ECA mantém-se dinâmico desde 1995. Ainda mais significativo, o congresso "Critical Management Studies", o primeiro do gênero, aconteceu no University of Manchester Institute of Science and Technology em 1999. É na lógica dessa efervescência que se inscreve a iniciativa da University of Lancaster, ao oferecer programas de doutorado e mestrado especificamente reservados aos ECA, ao passo que várias universidades inglesas integram, cada vez mais, a seus programas disciplinas com um conteúdo crítico. Paralelamente, observa-se também, durante a década de 1990, uma produção crescente de manuais críticos de administração (Thompson e McHugh, 1990; Aktouf, 1994; Fulop e Linstead, 1999; Mills e Simmons, 1999; Knights e Willmott, 1999; Smircich e Calás, 1995).

\section{Referências bibliográficas}

AKTOUF, O. Le management entre tradition et renouvellement. Montréal: Gaëtan Morin, 1994.

ALCADIPANI, R. e ALMEIDA, A. O feitiço incluiu o feiticeiro: uma análise sobre a implementação de um escritório-aberto. In: ENCONTRO ANUAL DA ASSOCIAÇÃO NACIONAL DOS PROGRAMAS DE PÓS-GRADUAÇÃO EM ADMINISTRAÇÃO, 24ํㅡ, 2000, Florianópolis. Anais... Florianópolis : Anpad, 2000

ALCADIPANI, R. e BRESLER, R. McDonalidização do ensino no Brasil. Carta Capital, São Paulo, n. 122, maio 1999.

ALTER, N. Inovação, risco e transgressão nas organizações. In: Davel, E. e Vergara, S. C. Gestão com pessoas e subjetividade. São Paulo: Atlas, 2001.
ALVESSON, M. e BILLING, Y. D. Understanding gender and organizations. Thousand Oaks : Sage, 1997.

ALVESSON, M. e DEETZ, S. Teoria crítica e abordagens pós-modernas para estudos organizacionais. In: Clegg, S., Hardy, C., Nord, W. R., Caldas, M., Fachin, R. e Fischer, T. (Eds.). Handbook de estudos organizacionais. São Paulo : Atlas, 1999.

ALVESSON, M. e DEETZ, S. Doing critical management research. London : Sage, 2000

ALVESSON, M. e WILLMOTT, H. Critical management studies. London : Sage, 1992a.

ALVESSON, M. e WILLMOTT, H. On the idea of emancipation in management and organization studies. Academy of Management Review, v. 17, n. 3, p. 432-64, 1992b.

ALVESSON, M. e WILLMOTT, H. Making sense of management: a critical introduction. London : Sage, 1996.

ANTHONY, P. Management education: ethics versus morality. In: Parker, M. (Ed.). Ethics and organization. London : Sage, 1998.

ANTONACOPOULOU, E. P. The power of critique: revisiting critical theory at the end of the century. First International Critical Management Studies Conference. Manchester : Umist, 1999.

BAHIA, M. e FERRAZ, M. Entre a exceção e a regra: a construção do feminino na polícia civil baiana. Organização \& Sociedade, v. 7, n. 18, p. $25-40,2000$

BARROSO, C. A chefia feminina na administração pública brasileira. Revista de Administração Pública, v. 24, n. 1, p. 12-34, 1990.

BAUMAN, Z. Intimations of posmodernity. London : Routledge, 1992.

BENDIX, R. Work and authority in industry. New York : Harper \& Row, 1956

BERTERO, C. O. Poder e organização: uma perspectiva brasileira. Colóquio de Estratégia e Organização. Zacatecas, 2000.

BERTERO, C. O., CALDAS, M e WOOD JR., T. Produção científica em administração de empresas: insinuações e contribuições para um debate local. Revista de Administração Contemporânea, v. †3, n. †1, p. 14778, 1999.

BERTERO, C. O. e KEINERT, T. M. M. A evolução da análise organizacional no Brasil (1961-1993). RAE - Revista de Administração de Empresas, v. 34, n. 3, p. 81-90, 1994.

BURNHAM, J. The managerial revolution. London : Penguin, 1945. 
BURRELL, G. e MORGAN, G. Sociological paradigms and organizational analysis elements of the sociology of corporate life. London : Heinemann, 1979.

CALÁS, M. e SMIRCICH, L. Do ponto de vista da mulher: abordagens feministas em estudos organizacionais. In: CLEGG, S., HARDY, C., NORD, W. R., CALDAS, M., FACHIN, R. e FISCHER, T. (Eds.). Handbook de estudos organizacionais. São Paulo : Atlas, 1999.

CARNEIRO, A. Teorias organizacionais: do ceticismo à consciência crítica. Revista de Administração Pública, v. 29, n. 2, p. 22-35, 1995.

CASTRO, R. Gênero nas organizações: os casos do projeto Axé da fundação Cidade Mãe em Salvador. In: ENCONTRO ANUAL DA ASSOCIAÇÃO NACIONAL DOS PROGRAMAS DE PÓS-GRADUAÇÃO EM ADMINISTRAÇÃO, 22º 1998 , Foz do Iguaçu. Anais... Foz do Iguaçu : Anpad, 1998.

CLEGG, S. e HARDY, C. Organização e estudos organizacionais. In: CLEGG, S., HARDY, C., NORD, W. R., CALDAS, M., FACHIN, R. e FISCHER, T. (Eds.). Handbook de estudos organizacionais. São Paulo : Atlas, 1999.

COOPER e BURRELL, G. Modernism, postmodernism and organization analysis: an introduction. Organization Studies, v. 9, n. 1, p. 15-43, 1988.

DAVEL, E. e CHENNOUFI, M. Les études critiques en management: un aperçu de la littérature récente. The Annual Conference of Administrative Sciences Association of Canada Proceedings (Organization Theory Division). London : Asac, 2001.

DELLAGNELO, E. e MACHADO-DA-SILVA, C. Novas formas organizacionais: onde se encontram evidências de ruptura com o modelo burocrático? Organização \& Sociedade, v. 7, n. 19, 2000.

FARAH, M. Reforma de políticas sociais no Brasil: experiências recentes de governos subnacionais. Revista de Administração, v. 33, n. 1, p. 15-29, 1998.

FARIA, J. H. e OLIVEIRA, S. N. Gestão da qualidade: a dimensão político-cognitiva-afetiva do desempenho organizacional. In: ENCONTRO ANUAL DA ASSOCIAÇÃO NACIONAL DOS PROGRAMAS DE PÓSGRADUAÇÃO EM ADMINISTRAÇÃO, 23o, 1999, Foz do Iguaçu. Anais... Foz do Iguaçu : Anpad, 1999.

FOURNIER, V. e GREY, C. At the critical moment: conditions and prospects for critical management studies. Human Relations, v. 53, n. 1, p. $7-32,2000$

FREITAS, M. E. Cultura organizacional: o doce controle no clube dos raros. In: ENCONTRO ANUAL DA ASSOCIAÇÃO NACIONAL DOS PROGRAMAS DE PÓS-GRADUAÇÃO EM ADMINISTRAÇÃO, 20ํ, 1996, Rio de Janeiro. Anais... Rio de Janeiro : Anpad, 1996.

FULOP \& LINSTEAD, S. Management: a critical text. London: Macmillan Press, 1999.

GABRIEL, Y. The state of critique in organizational theory. Human Relations, v. 54, n. 1, p. 23-30, 2001.
HASSARD, J., HOLLIDAY, R. e WILLMOTT, H. Body and organization. London : Sage, 2000

JACOBSON, S. W. e JACQUES, R. Destabilizing the field: poststructuralist knowledge-making strategies in a postindustrial era. Journal of Management Inquiry, v. 6, n. 1, p. 42-59, 1997.

JERMIER, J. M. Introduction: critical perspectives on organizational control. Administrative Science Quarterly, v. 43, p. 235-56, 1998.

KNIGHTS, D. e MORGAN, G. Corporate strategy, organizations and subjectivity: a critique. Organization Studies, v. 12, n. 2, p. 251-73, 1991.

KNIGHTS, D. e WILLMOTT, H. Management lives: power and identity in work organizations. London : Sage, 1999.

LENGLER, J., VIEIRA, M. e FACHIN, R. Um exercício de desconstrução do conceito e da prática de segmentação de mercado com base no gênero e na etnia: o que nos ensina Woody Allen sobre a hegemônica teoria de marketing? In: ENCONTRO ANUAL DA ASSOCIAÇÃO NACIONAL DOS PROGRAMAS DE PÓS-GRADUAČ̃̃O EM ADMINISTRAČ̃̃O, 24으, 2000, Florianópolis. Anais... Florianópolis : Anpad, 2000.

LUNARDI, V. e MAZZILLI, C. Processo de trabalho na área de enfermagem: uma abordagem psicanalítica. Revista de Administração, v. 31, n. 3, p. 63-71, 1996

MACHADO-DA-SILVA, C., CUNHA, V. C. e AMBONI, N. Organizações: o estado da arte da produção acadêmica no Brasil. In: ENCONTRO ANUAL DA ASSOCIAÇÃO NACIONAL DOS PROGRAMAS DE PÓS-GRADUAÇÃO EM ADMINISTRAÇÃO, 14oㅜ 1990, Florianópolis. Anais... Florianópolis : Anpad, 1990.

MARTINS, G. Epistemologia da pesquisa em administração. In: ENCONTRO ANUAL DA ASSOCIAÇÃO NACIONAL DOS PROGRAMAS DE PÓSGRADUAÇÃO EM ADMINISTRAÇÃO, 20º , 1996, Rio de Janeiro. Anais... Rio de Janeiro : Anpad, 1996.

MILLS, C. W. The power elite. New York : Oxford University Press, 1956.

MILLS e SIMMONS. Reading organization theory: a critical approach to the study of organizational behaviour and structure. Toronto : Garamond Press, 1999

MINGERS, J. What is it to be critical? Teaching a critical approach to management undergraduates. Management Learning, v. 31, n. 2, p. 219$37,2000$.

PAES DE PAULA, A. P. e WOOD JR., T. Divertimentos administrativos. In: ENCONTRO ANUAL DA ASSOCIAÇÃO NACIONAL DOS PROGRAMAS DE PÓS-GRADUAÇÃO EM ADMINISTRAÇÃO, 25으, 2000, Campinas. Anais... Campinas : Anpad, 2000.

POSTER, M. Critical theory and post structuralism: in search of a context. New York : Cornell University Press, 1989. 
PRESTES MOTTA, F. C. O poder disciplinar nas organizações formais. RAE - Revista de Administração de Empresas, v. 21, n. 4, p. 33-41, 1981.

PRESTES MOTTA, F. C. Organização e poder: empresa, estado e escola. São Paulo : Atlas, 1986.

PRESTES MOTTA, F. C. As empresas e a transmissão da ideologia. RAE Revista de Administração de Empresas, v. 32, n. 5, p. 38-47, 1992.

PRESTES MOTTA, F. e ALCADIPANI, R. Jeitinho brasileiro, controle social e competição. RAE - Revista de Administração de Empresas, v. 39, n. 1, p. 420, 1999.

RAMOS, A. G. A nova ciência das organizações: uma nova ciência das organizações. Rio de Janeiro : Editora da FGV, 1981.

RAMOS, A. G. Administração e contexto brasileiro. Rio de Janeiro : Editora da FGV, 1983.

RODRIGUES, S. Commodification of scientific knowledge and deification of innovation: implication for knowledge in management. In: ENCONTRO ANUAL DA ASSOCIAÇÃO NACIONAL DOS PROGRAMAS DE PÓSGRADUAÇÃO EM ADMINISTRAÇÃO, 14ํ, 1990, Florianópolis. Anais... Florianópolis : Anpad, 2000.

RODRIGUES, S. B. e CARRIERI, A. P. A tradição anglo-saxônica nos estudos organizacionais brasileiros. In: ENCONTRO DE ESTUDOS ORGANIZACIONAIS, 1ํ, 2000, Curitiba. Anais... Curitiba, 2000.
SEGNINI, L. A liturgia do poder: trabalho e disciplina. São Paulo : Editora da PUC-SP, 1988.

SMIRCICH, L. e CALÁS, M. Critical perspectives on organization and management. Aldershot: Dartmouth, 1995.

STEIL, V. Organizações, gênero e posição hierárquica: compreendendo o fenômeno do teto de vidro. Revista de Administração, v. 32, n. 3, p. 27 43, 1997.

THOMPSON e MCHUGH, Work organizations: a critical introduction. London : McMillan, 1990.

TOWNLEY, B. Conhecimento e poder nas organizações. In: DAVEL, E. e VERGARA, S. C. Gestão com pessoas e subjetividade. São Paulo : Atlas, 2001.

TRAGTENBERG, M. Burocracia e ideologia. São Paulo : Ática, 1974.

TRAGTENBERG, M. Administração, poder e ideologia. São Paulo : Moraes, 1980.

VERGARA, S. A hegemonia americana em estudos organizacionais. Revista de Administração Pública, v. 35, n. 2, p. 63-77, 2001.

VERGARA, S. C. e BRANCO, P. D. Empresa humanizada: a organização necessária e possível. RAE - Revista de Administração de Empresas, v. 41, n. 2, p. 20-30, 2001

WATSON, T. In search of management: culture, chaos and control in managerial work. London : Routledge, 1994.

\section{Eduardo Davel}

Doutorando na École des HEC de Montréal. Pesquisador da Télé-université, Université du Québec. Interesses de pesquisa: organizações familiares; organizações culturais; dinâmicas sociais, políticas, culturais e emocionais das organizações; abordagens críticas e relacionais da administração e comportamento gerencial.

E-mail: edavel@teluq.uquebec.ca

Endereço: 3505, Rue Sainte Famille, ap. 1502 - Montréal (Québec) H2X 2L3 Canadá.

\section{Rafael Alcadipani}

Professor do Departamento de Administração Geral e Recursos Humanos da FGV-EAESP e Professor da ESPM-SP.

Mestre em Administração pela FGV-EAESP. Interesses de pesquisa: estudos críticos e administração, cultura organizacional e cultura brasileira e pós-estrututuralismo e análise das organizações

E-mail: ralcadipani@fgvsp.br

Endereço: Av. Nove de Julho, 2022 - $9^{\circ}$ Andar - Bela Vista, CEP 01313-902, São Paulo, SP. 